\title{
Theoretical Modeling of Rock Breakage by Hydraulic and Mechanical Tool
}

\author{
Hongxiang Jiang, 1 Changlong Du, ${ }^{1}$ Songyong Liu, ${ }^{1}$ and Liping Wang ${ }^{2}$ \\ ${ }^{1}$ College of Mechanical and Electrical Engineering, China University of Mining and Technology, Xuzhou 221116, China \\ ${ }^{2}$ School of Computer Science, Engineering and Mathematics, Flinders University, Adelaide, SA 5042, Australia
}

Correspondence should be addressed to Changlong Du; changlong568du@163.com

Received 28 June 2014; Accepted 22 October 2014; Published 9 November 2014

Academic Editor: Yi-Kuei Lin

Copyright (c) 2014 Hongxiang Jiang et al. This is an open access article distributed under the Creative Commons Attribution License, which permits unrestricted use, distribution, and reproduction in any medium, provided the original work is properly cited.

\begin{abstract}
Rock breakage by coupled mechanical and hydraulic action has been developed over the past several decades, but theoretical study on rock fragmentation by mechanical tool with water pressure assistance was still lacking. The theoretical model of rock breakage by mechanical tool was developed based on the rock fracture mechanics and the solution of Boussinesq's problem, and it could explain the process of rock fragmentation as well as predicating the peak reacting force. The theoretical model of rock breakage by coupled mechanical and hydraulic action was developed according to the superposition principle of intensity factors at the crack tip, and the reacting force of mechanical tool assisted by hydraulic action could be reduced obviously if the crack with a critical length could be produced by mechanical or hydraulic impact. The experimental results indicated that the peak reacting force could be reduced about $15 \%$ assisted by medium water pressure, and quick reduction of reacting force after peak value decreased the specific energy consumption of rock fragmentation by mechanical tool. The crack formation by mechanical or hydraulic impact was the prerequisite to improvement of the ability of combined breakage.
\end{abstract}

\section{Introduction}

Rock breakage by mechanical or hydraulic action has been widely used in fields such as coal, oil, coalbed methane, and shale gas. Rock fragmentation performance by mechanical or hydraulic method has direct effect on the efficiency of coal mining and oil and gas exploration; thus there was important significance on investigating rock breakage process [1-4]. Rock breakage by coupled mechanical and hydraulic action has been developed over the past several decades, and it has been proven to improve the rock breakage ability, reduce the reacting force, and extend service life of mechanical tool. Nowadays, the combined action has been a considerable research area for rock fragmentation [5-7]. For breakage rock by mechanical or hydraulic method, many researchers have developed several mathematical models to express the peak reacting force of mechanical tool. The mathematical models based on maximum tensile stress theory, Mohr-Coulomb failure criterion, and principle of energy dissipation were developed by a few scholars [8-12], which could predicate the peak reacting force of mechanical tool according to cutting parameters and rock properties in rock breakage. Bowden and Brunton [13] and Momber [14] investigated the deformation and damage characteristics of rock and cement materials under high-velocity liquid impact, and the relations between the damage extent and tensile strength, fracture toughness, and other mechanical parameters were investigated. Contributions to theoretical modeling of rock breakage by water pressure have been made continuously since the 1960s. These authors made various simplifying assumptions, for instance, regarding fluid flow, fracture shape, and leakage velocity from the fracture, and all these present analytical solutions were in the frame of linear fracture mechanics [1517]. But so far, the investigations on rock breakage by coupled mechanical and hydraulic action mainly depended on experimental and numerical methods [5-7, 18-20]; however, there were few literatures about the mathematical model. When the hydraulic action was introduced to these present mathematical models of mechanical tool, there were some limitations because the reacting forces were all obtained 


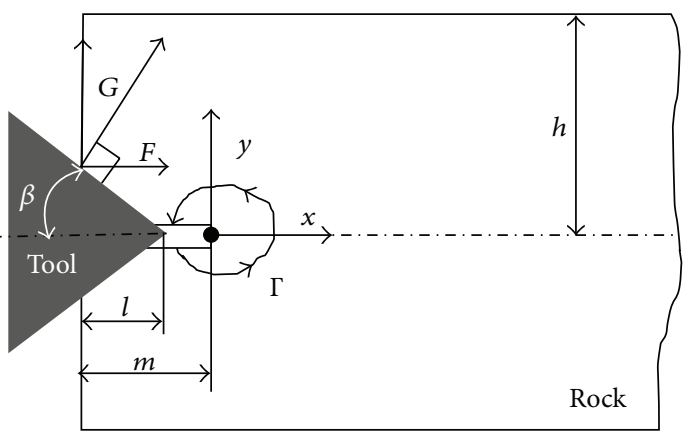

FIGURE 1: Sketch of rock fragmentation.

according to the limit equilibrium condition rather than a dynamic process. The linear elastic fracture mechanics could describe the rock fracture well, and Boussinesq's problem could be used to solve the elastic deformation of rock due to the extrusion action caused by mechanical tool. Therefore, a theoretical model of rock breakage by mechanical tool was established according to the linear elastic fracture mechanics and the solution of Boussinesq's problem; then another theoretical model was developed by introducing hydraulic action. With the experimental acting force of mechanical and mechanical-hydraulic tool, the two developed theoretical models were analyzed, and they could provide some basis for designing or studying the rock breakage by mechanical or mechanical-hydraulic action.

\section{Theoretical Modeling of Rock Breakage by Mechanical Tool}

2.1. Assumptions of Rock Breakage by Mechanical Tool. According to the rock breakage by mechanical tool, we would make some assumptions: (a) the carbide tip of mechanical tool approximately penetrated into the rock vertically, and the continuous elastic deformation of rock was produced in the formation of crushing zone; (b) the small rock debris were ignored before the formation of big rock fragment, and the rock deformed continuously before the crack initiation and propagation; (c) the rock failure was controlled by open fracture mode without slip and tear modes, and the crack was regarded as the ideal linear elasticity; (d) the carbide tip of mechanical tool was an ideal circular cone, and the friction force between rock and mechanical tool was ignored [8].

2.2. Mechanical Analysis of Rock Fracture. According to the assumptions of rock breakage by mechanical tool, the sketch of rock fragmentation is shown in Figure 1. The rock was regarded as the homogeneous and isotropic elastic material. A crack was produced by mechanical tool extruding rock, and it was parallel to the feeding direction of mechanical tool. The two-dimensional stress and strain field around the crack was produced by the extrusion action on rock by mechanical tool. The rock fracture was determined by the upward pulling force $G$ due to the mechanical action, and the crack would initiate and propagate when the intensity factor at crack tip exceeded mode I fracture toughness of the rock.
The $J$-integral was proposed by Rice in 1968, which was a curvilinear integral around the crack tip, and it was path independent [21]. The J-integral had great significance on the development of elastic-plastic fracture mechanics, and it has been an important parameter for linear elastic and elasticplastic fracture mechanics at present. Therefore, the $J$-integral was adopted to investigate the rock fracture behavior in rock breakage by mechanical tool. According to the conservation properties of $J$-integral method, it had no relation with the integration path. A circular (with crack tip as the origin) was regarded as the integration path for reducing the solving difficulty, and the $J$-integral value of the crack tip can be expressed as

$$
J=\frac{1-v^{2}}{E}\left(K_{\mathrm{I}}^{2}+K_{\mathrm{II}}^{2}\right),
$$

where $J$ is the $J$-integral value and $v$ is the rock Poisson ratio; $E$ represents the elastic modulus of rock; $K_{\mathrm{I}}$ represents the stress intensity factor at crack tip under mode I fracture; $K_{\mathrm{II}}$ represents the stress intensity factor at crack tip under mode II fracture.

According to the assumptions of rock breakage, the rock failure was determined by open fracture mode without slip and tear modes; thus the rock fracture can be simplified as the mechanical model of cantilever beam. About the mechanical model of cantilever beam in two dimensions, the length and height were equal to $l$ and $h$, respectively. We have noted that energy variations are expressible in terms of the change in load deflection curves with increasing notch size and that for linear behavior [22]

$$
-\frac{d Q}{d l}=\frac{1}{2} G \frac{\partial \delta(G, l)}{\partial l},
$$

where $Q$ represents the bending strain energy of cantilever beam; $\delta$ is the deflection of cantilever beam under the upward pulling force, and it is equal to $4 G l^{3} / E h^{3}$ in two dimensions.

According to the definition of $J$-integral, the $J$-integral value is equal to the energy release rate under linear elastic condition. For the model of cantilever beam, the crack strain energy was mainly concentrated in the range of crack length with the bending deflection energy form. Thus, the stress intensity factor at crack tip of mode I fracture caused by the upward pulling force could be obtained by combining (1) and (2), and the relations between the stress intensity factor and beam length, beam height, and pulling force were shown as follows:

$$
K_{\mathrm{I}}=\frac{\sqrt{6} G l}{\sqrt{1-v^{2}} h^{3 / 2}} .
$$

With Poisson's ratio of 0.3 , the variation relationships between the stress intensity factor at crack tip and beam length, beam height, and pulling force are shown in Figure 2. From the figure, the stress intensity factor at crack tip under mode I fracture decreased with the cutting depth when the pulling force and beam length were constant, which indicated that the crack propagation was more difficult due to higher cutting depth. The bigger pulling force made the stress 


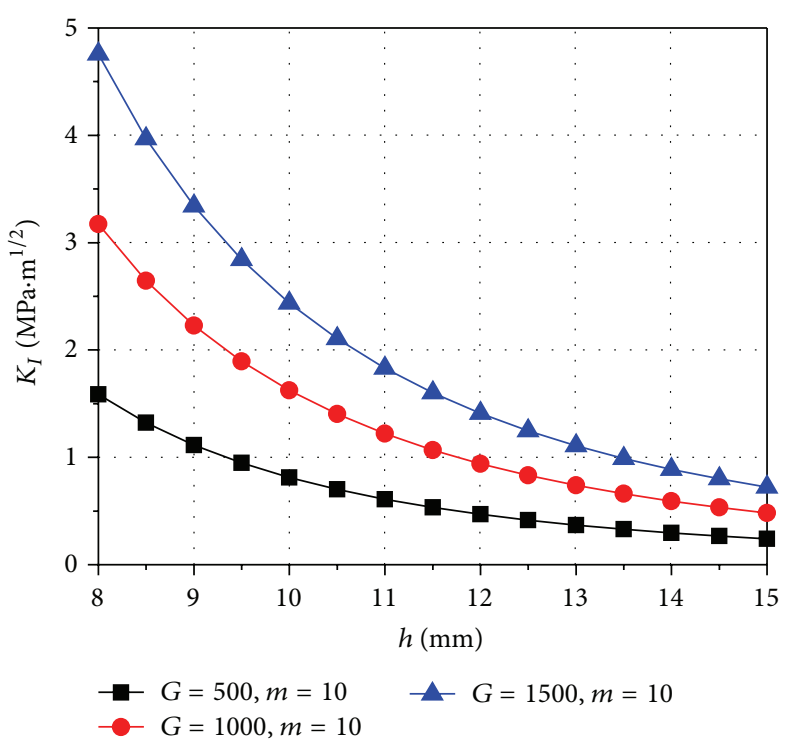

(a) Cutting depth

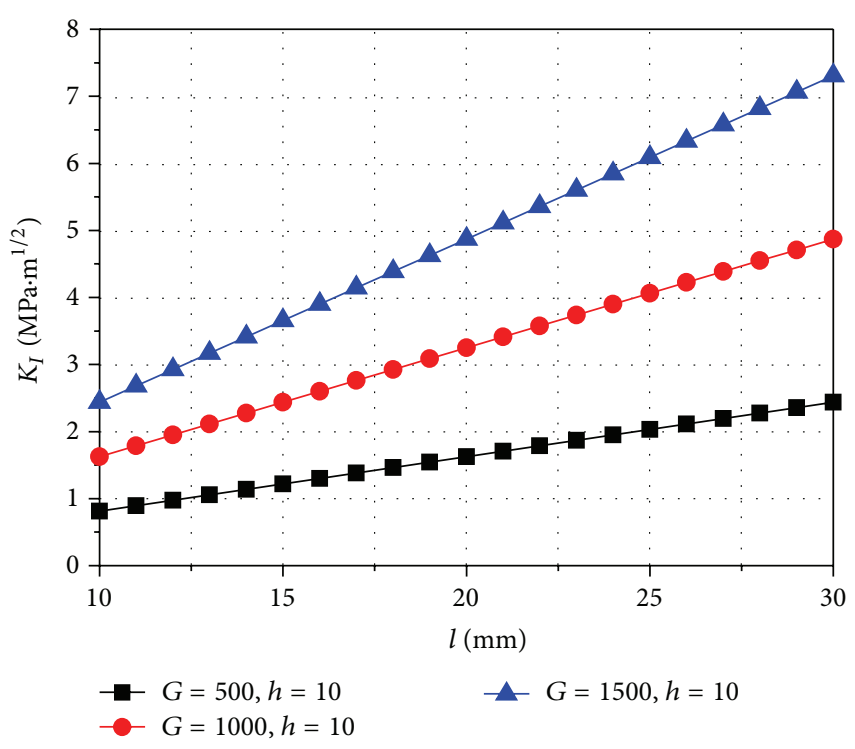

(b) Crack length

FIGURE 2: Stress intensity factor at crack tip of mode I fracture.

intensity factor greater when the cutting depth and crack length were constant and caused the crack to propagate easily. When the cutting depth and pulling force were constant, the stress intensity factor increased with the crack length. Therefore, it indicated that the crack would enter into the unstable fracture when the crack was initiated, and the phenomenon could be verified through the reacting force reduction after the peak point [23].

Due to ignoring the friction between rock and mechanical tool, there would be a relation between the horizontal extrusion force and the upward pulling force as follows:

$$
\frac{F}{G}=\tan \beta,
$$

where $F$ is the reacting force of mechanical tool in horizontal direction; $\beta$ is the half cone angle of tool carbide tip.

By combining (3) and (4), the reacting force of mechanical tool in horizontal direction after the crack initiation can be expressed as

$$
F=\frac{K_{\mathrm{IC}} \tan \beta}{l} \sqrt{\frac{1-v^{2}}{6}} h^{3 / 2} .
$$

2.3. Mechanical Analysis of Rock Elastic Deformation. Based on linear elastic fracture mechanics and cantilever beam model, the relationship between the reacting force and cutting depth, crack length, and stress intensity factor under mode I fracture, Poisson's ratio was set up, but the tool penetration depth could not be determined when the crack initiated. Equation (5) only can describe the relation between the reacting force and crack length, cutting depth, and so forth. Therefore, mechanical analysis between rock and tool before crack initiation should be considered. According to the assumptions of rock fragmentation, the rock sustained the

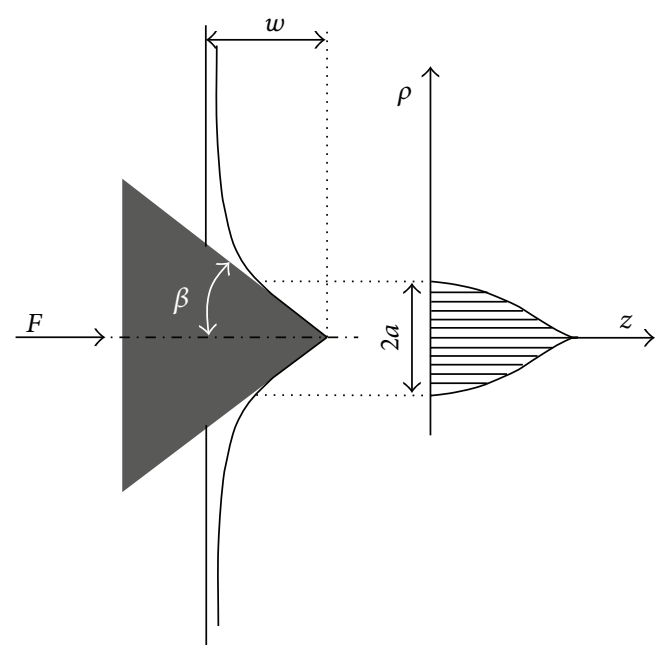

FIGURE 3: Sketch of indenter squeezing elastic body.

elastic deformation in the formation of crushing zone, and the mechanical tool acted on rock as shown in Figure 3. In 1885, French mathematician Boussinesq used elasticity theory to solve the stress and strain field when a vertical concentrated load acted on the elastic material; then the problem was called Boussinesq's problem [24]. Afterwards, Chiaia solved the reacting force when the indenter with different shapes squeezed the semi-infinite elastic body based on the solution of Boussinesq's problem [25]. In addition, the expressions of penetration depth and reacting force of indenter are as follows:

$$
\begin{gathered}
w=\int_{0}^{1} \frac{f^{\prime}(x) \mathrm{d} x}{\sqrt{1-x^{2}}}, \\
P=\frac{4 \mu a}{1-v} \int_{0}^{1} \frac{x^{2} f^{\prime}(x) \mathrm{d} x}{\sqrt{1-x^{2}}},
\end{gathered}
$$




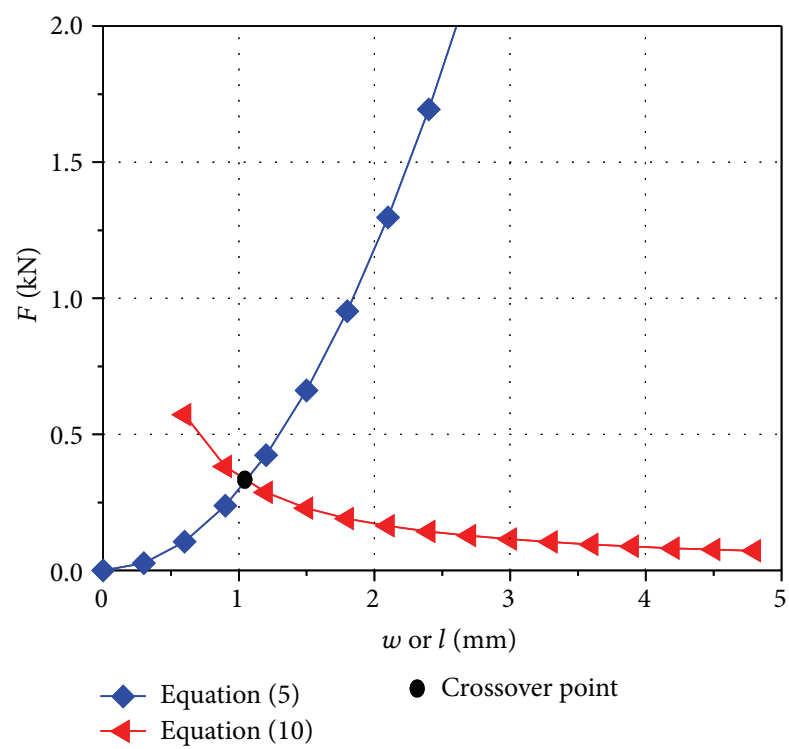

(a) Cutting depth of $8 \mathrm{~mm}$

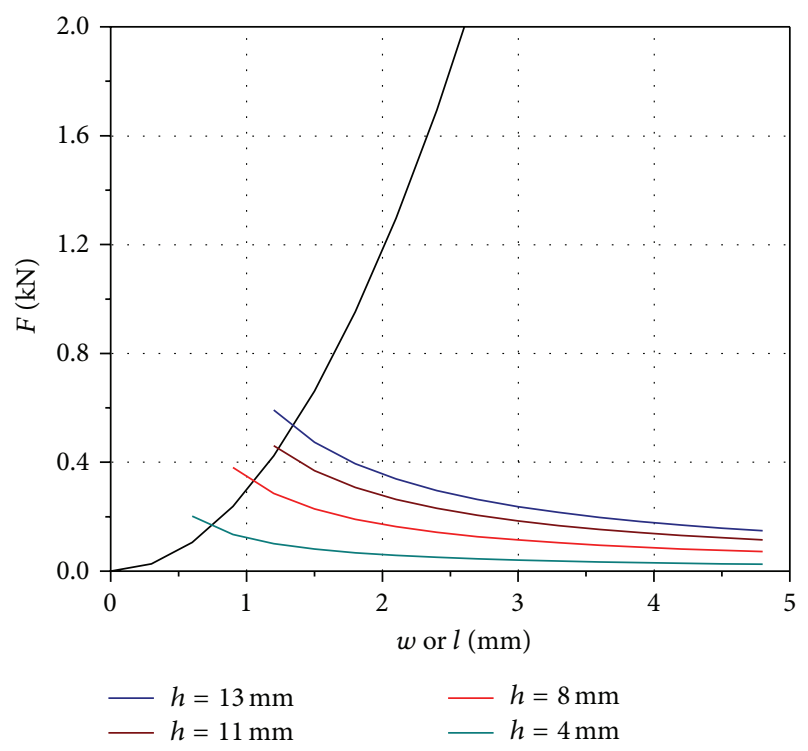

(b) Different cutting depth

FIGURE 4: The reacting force of mechanical tool in horizontal direction.

where $w$ is the penetration depth of indenter; $\mu$ is the shear modulus of rock; $a$ represents the contact radius between the indenter and rock; $f(x)$ is a function for defining the indenter profile, and $w(\rho)=f(\rho / a), x=\rho / a$; $P$ represents the reacting force of indenter.

Because the carbide tip of mechanical tool was similar to cone indenter, the function $f(x)$ can be expressed as

$$
f(x)=\varepsilon x=a x \cot \beta \text {. }
$$

Submitting (7) into (6), the penetration depth and reacting force of mechanical tool could be obtained as follows:

$$
\begin{gathered}
w=\frac{1}{2} \pi \varepsilon=\frac{1}{2} \pi a \cot \beta \\
P=\frac{\pi \eta a^{2}}{1-v} \cot \beta=\frac{2 E \tan \beta w^{2}}{\pi\left(1-v^{2}\right)} .
\end{gathered}
$$

By combining (8) and (9), the reacting force of mechanical tool in two dimensions according to Figure 3 can be expressed as

$$
F=\frac{2 E \tan \beta}{\pi^{2}\left(1-v^{2}\right)} w^{2} .
$$

According to (10), the reacting force of mechanical tool in horizontal direction was proportional to the elastic modulus of rock, the half cone angle of tool carbide tip, and the square of tool penetration depth.

2.4. Experimental Verification. On the basis of the above analysis, the rock breakage by mechanical tool consisted of elastic deformation and crack propagation stages; thus the reacting force model of mechanical tool included two stages as follows:

$$
F=\left\{\begin{array}{l}
\frac{2 E \tan \beta}{\pi^{2}\left(1-v^{2}\right)} w^{2} \quad(\text { elastic deformation stage }) \\
\frac{K_{\mathrm{IC}} \tan \beta}{l} \sqrt{\frac{1-v^{2}}{6}} h^{3 / 2} \quad \text { (crack propagation stage). }
\end{array}\right.
$$

A relatively homogeneous rock was selected in this study, for which some of the basic properties have been presented in [11]. The parameters of the rock were as follows: density was $2250 \mathrm{~kg} / \mathrm{m}^{3}$; fracture toughness under mode I was $0.91 \mathrm{MPa} \cdot \mathrm{m}^{1 / 2}$; compressive strength was $56.5 \mathrm{MPa}$; tensile strength was $4.89 \mathrm{MPa}$; elastic modulus was $1.3 \mathrm{GPa}$. Then, the reacting force of mechanical tool in rock breakage could be obtained through (11). With cutting depth of $8 \mathrm{~mm}$, the tool reacting force versus penetration depth or crack length is shown in Figure 4(a); thus the crossover point of these two curves is the peak reacting force. The variation of reacting force was similar to the experimental cutting force, and they all offered upgrade firstly and then descending latter tendency. The reacting forces in two dimensions with different cutting depth are shown in Figure 4(b), and they can be translated to that in three dimensions for comparing with the experimental results. The rock fragmentation experiments by mechanical tool were done by Bao et al. [11], and the reacting forces with different cutting depth were provided. The theoretical and experimental peak reacting forces are shown in Figure 5, and the regression relation is obtained by the least squares method. The correlation coefficient is equal to 0.99 , which indicates that the result of linear regression analysis is correct, and it also confirms the correctness of theoretical model of rock breakage by mechanical tool. The line slope of 1.15 means that the theoretical and experimental 


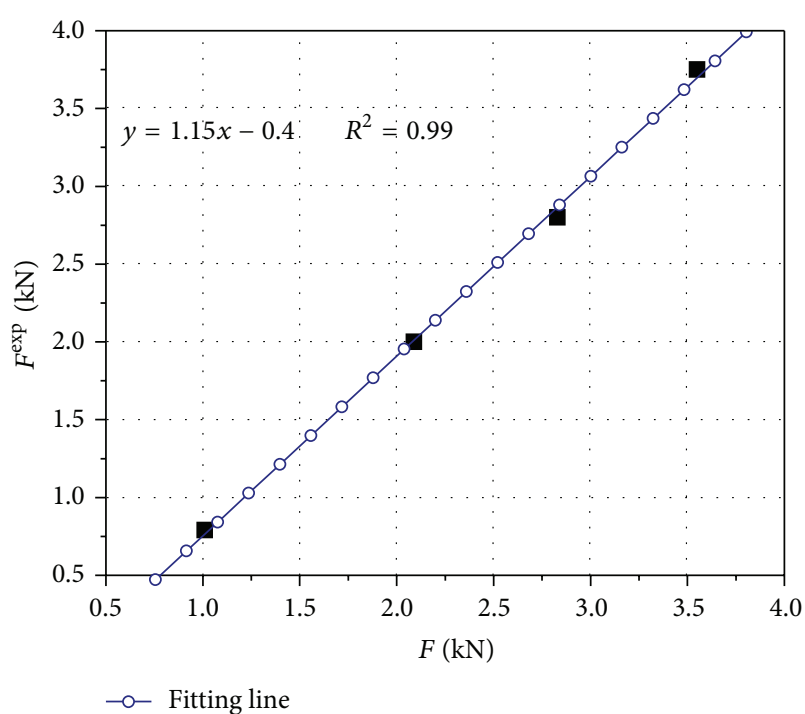

FIGURE 5: Relationship between theoretical and experimental peak reacting force [11].

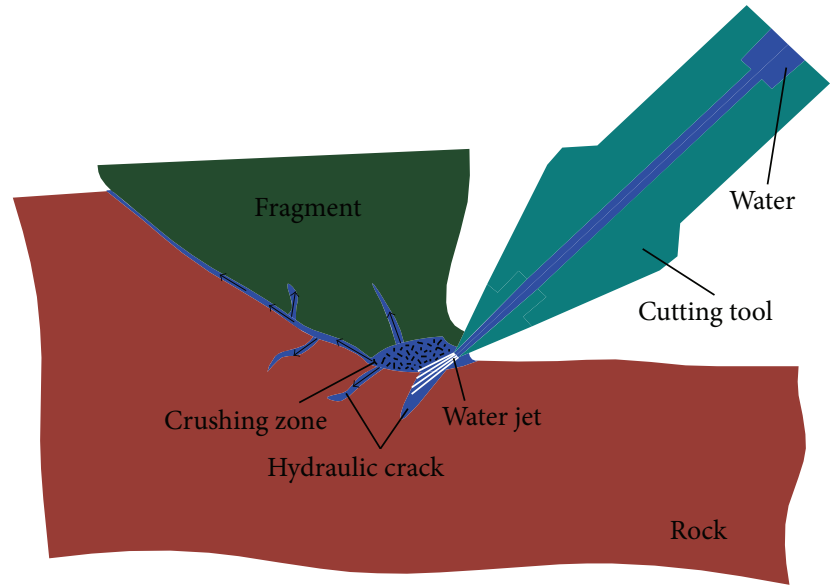

FIGURE 6: Rock breakage by coupled mechanical and hydraulic action.

peak reacting forces are close and shows that the developed model could predicate the peak reacting force of mechanical tool accurately. In addition, it could provide some basis for modeling the theoretical model of rock breakage by coupled mechanical and hydraulic action.

\section{Theoretical Modeling of Rock Breakage by Coupled Mechanical and Hydraulic Action}

3.1. Assumptions of Rock Fragmentation by Coupled Mechanical and Hydraulic Action. The rock breakage process by coupled mechanical and hydraulic action is shown in Figure 6 $[26,27]$; we would make some assumptions of this mechanical problem: (a) the process of rock breakage was regarded as a quasi static process; (b) the crack was treated as an ideal crack, which was produced by coupled mechanical or hydraulic action: the crack size was far smaller than the rock size, and the size effect on rock breakage was ignored; (c) the water pressure acting on crack surfaces due to hydraulic action was of uniform distribution, and the behavior of water flow in crack was ignored; (d) the rock breakage by coupled mechanical and hydraulic action was induced by mode I fracture, and the crack would propagate if the stress intensity factor on the crack tip exceeded the fracture toughness of mode I fracture or the tensile stress at crack tip reached the rock tensile strength.

3.2. Mechanical Analysis by Combined Rock Breakage. The sketch of rock fragmentation by coupled mechanical and hydraulic action is shown in Figure 7(a). In two dimensions, an upward pulling force acted on rock, and the crack surfaces were subjected to the water pressure of uniform distribution. Thus, the rock would break by the upward pulling force combined with water pressure. Figure 7(b) is the simplified model of rock fragmentation by mechanical tool; its reacting force in horizontal direction is translated to the upward pulling force for introducing the hydraulic action to rock breakage by mechanical tool. Figure 7(c) is the simplified model of rock fragmentation by hydraulic action, and the water pressure is regarded to be of uniform distribution on crack surfaces.

Because linear elastic fracture mechanics was developed based on elastic theory, the stress field at crack tip could be solved by adding the stress produced by several loads acting on crack separately; thus it indicated that the stress intensity factor possessed the superposition characteristic [28]. As shown in Figure 7, the rock is affected by the upward pulling force and the water pressure of uniform distribution, which could be equivalent to the rock fragmentation by coupled mechanical and hydraulic action. According to the fracture mechanics [29], the stresses at the crack tip can be expressed as

$$
\begin{gathered}
\sigma_{x}=\frac{K_{\mathrm{I}}}{\sqrt{2 \pi r}} \cos \frac{\theta}{2}\left(1-\sin \frac{\theta}{2} \sin \frac{3 \theta}{2}\right), \\
\sigma_{y}=\frac{K_{\mathrm{I}}}{\sqrt{2 \pi r}} \cos \frac{\theta}{2}\left(1+\sin \frac{\theta}{2} \sin \frac{3 \theta}{2}\right), \\
\sigma_{x y}=\frac{K_{\mathrm{I}}}{\sqrt{2 \pi r}} \cos \frac{\theta}{2} \sin \frac{\theta}{2} \cos \frac{3 \theta}{2} .
\end{gathered}
$$

For the problem of rock breakage by coupled mechanical and hydraulic action, the stress intensity factor at crack tip of mode I fracture can be expressed as

$$
K_{\mathrm{I}}=K_{\mathrm{IP}}+K_{I W},
$$

where $K_{I P}$ is the stress intensity factor at crack tip of mode I fracture by mechanical tool; $K_{I W}$ represents the stress intensity factor at crack tip of mode I fracture by water pressure.

Similarly, the stress at the crack tip in $y$ direction was equal to the sum of the stresses caused by mechanical tool and water pressure:

$$
\sigma_{y T}=\sigma_{y P}+\sigma_{y W}
$$




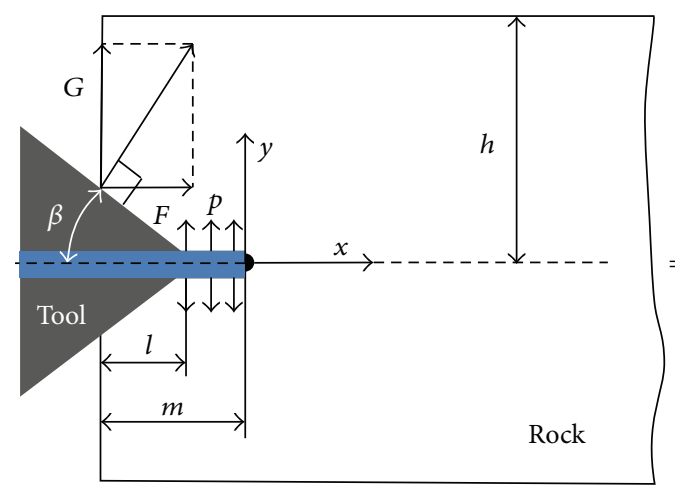

(a) Rock breakage by coupled mechanical and hydraulic action

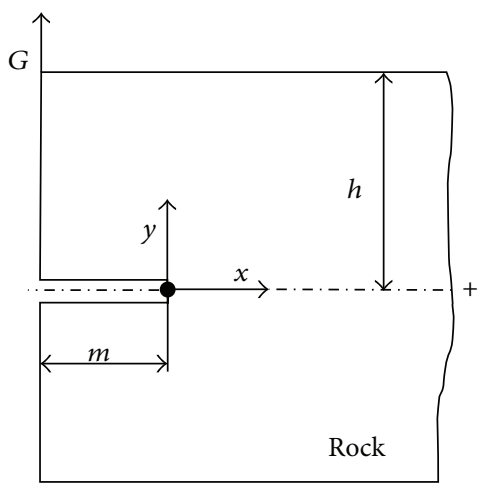

(b) Rock fragmentation by mechanical action

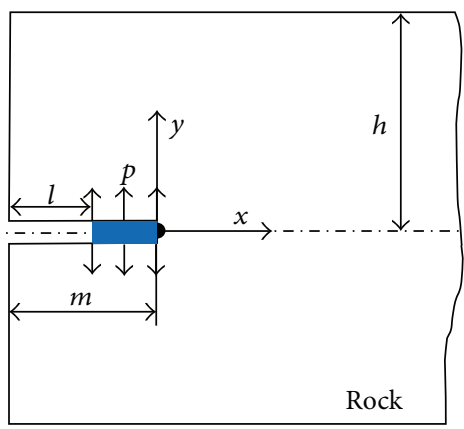

(c) Rock fragmentation by hydraulic action

FIGURE 7: Sketch of combined rock breakage and the superposition principle.

According to the criterion for crack propagation, the percentage reduction of reacting force in rock breakage by coupled mechanical and hydraulic action can be expressed as $\eta=\left\{\begin{array}{l}\frac{K_{\mathrm{IC}}-K_{\mathrm{IP}}}{K_{\mathrm{IC}}} \times 100 \%=\frac{K_{\mathrm{IW}}}{K_{\mathrm{IC}}} \times 100 \% \text { (mode I fracture criterion) } \\ \frac{\sigma_{y}-\sigma_{y P}}{\sigma_{y}} \times 100 \%=\frac{\sigma_{y W}}{\sigma_{y}} \times 100 \% \text { (maximum tensile stress criterion), }\end{array}\right.$

where $\sigma_{y T}$ is the tensile stress at crack tip; $\sigma_{y P}$ is the stress at crack tip caused by mechanical tool; $\sigma_{y W}$ is the stress at crack tip caused by water pressure; $\sigma_{y}$ represents the rock tensile strength.

According to fracture mechanics, the stress intensity factor at crack tip under mode I fracture by water pressure in Figure 7(c) can be expressed as [30]

$$
K_{\mathrm{IW}}=\frac{2}{\pi} \cos ^{-1}\left(\frac{l}{m}\right) p \sqrt{\pi m}
$$

Submitting (16) into (15), the percentage reduction of reacting force by coupled mechanical and hydraulic action can be expressed as

$$
\eta=\frac{K_{\mathrm{IW}}}{K_{\mathrm{IC}}} \times 100 \%=\frac{2}{\pi K_{\mathrm{IC}}} \cos ^{-1}\left(\frac{l}{m}\right) p \sqrt{\pi m} \times 100 \% .
$$

Appling (3) and (16) to (13), the stress intensity factor at crack tip of mode I fracture by coupled mechanical and hydraulic action is as follows:

$$
K_{\mathrm{I}}=\frac{\sqrt{6} G m}{\sqrt{1-v^{2}} h^{3 / 2}}+\frac{2}{\pi} \cos ^{-1}\left(\frac{l}{m}\right) p \sqrt{\pi m} .
$$

The crack would propagate if the stress intensity factor at crack tip of mode I fracture exceeded mode I fracture toughness of the rock; thus the reacting force of mechanical tool in breakage process by coupled mechanical and hydraulic action can be expressed as

$$
F=\frac{\left[K_{\mathrm{IC}}-(2 / \pi) \cos ^{-1}(l / m) p \sqrt{\pi m}\right] \sqrt{1-v^{2}} h^{3 / 2} \tan \beta}{\sqrt{6} m} .
$$

According to (17), the percentage reduction of reacting force by coupled mechanical and hydraulic action was determined by mode I fracture toughness, water pressure in crack, crack length, length of water pressure acting on crack, and so on. Some research results have confirmed that the crushing size and damage zone were related with hydraulic diameter, hydraulic impact velocity, rock properties, and so on $[31,32]$, but the crack length caused by hydraulic impact and water flow in crack were solved difficultly. Therefore, the penetration depth by mechanical tool and the crack length by coupled mechanical and hydraulic action could not be solved in (19). In order to investigate the effect of mechanical and hydraulic action on rock breakage, we assumed that a crack with a critical length could be produced by hydraulic impact in tool feeding direction, and the water pressure acted on the crack surface with uniform distribution. According to the theoretical result in this paper and numerical result in literature [4], the penetration depth by mechanical tool was very small when the rock fractured. For a case, the parameters in rock breakage process were as follows: the penetration depth was $2 \mathrm{~mm}$; the cutting depth was $8 \mathrm{~mm}$; the mode I fracture toughness of rock was $2 \mathrm{MPa} \cdot \mathrm{m}^{1 / 2}$. The percentage reduction of reacting force in rock breakage process by coupled mechanical and hydraulic action with different water pressure versus crack length is shown in Figure 8; it shows that the reacting force of mechanical tool could be reduced obviously by combined rock breakage. The percentage reduction of reacting force decreased with water pressure in crack, and it could reach over 50\% when the water pressure is equal to $10 \mathrm{MPa}$. Actually, it was difficult to inject the water with certain pressure into the crack ideally and ensure that the water did not spill from the contact zone between mechanical tool and rock; thus the water pressure was small than that of ideal condition. Accordingly, the percentage reduction of reacting force was less than that calculated according to (17). Equation (19) described the variation of reacting force of mechanical tool with hydraulic action assistance, but we have confirmed that the peak reacting force was determined by rock elastic deformation and crack propagation stages. Therefore, the produced crack 


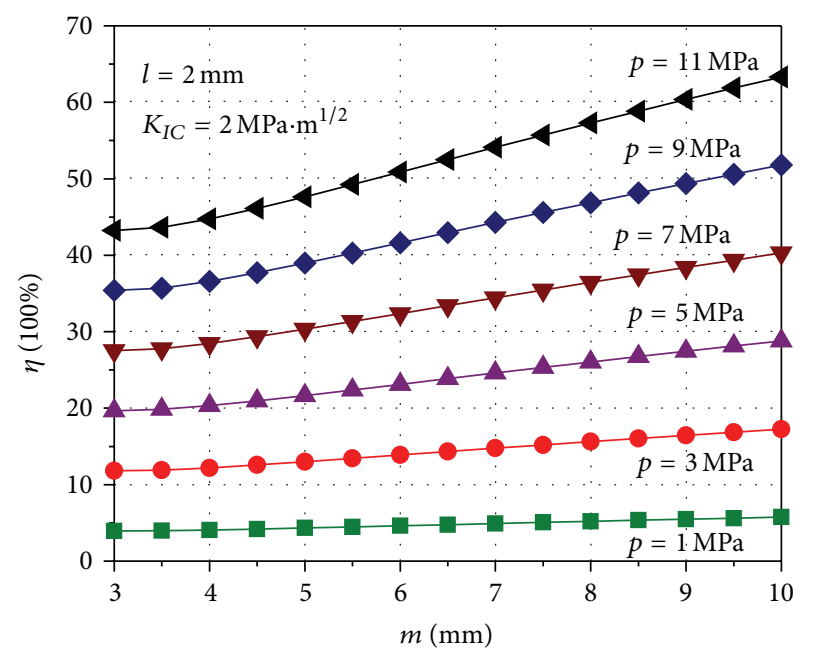

FIGURE 8: The percentage reduction of reacting force with different water pressure.

length by coupled mechanical and hydraulic action was the key for improving the percentage reduction of reacting force.

3.3. Experiments and Discussion. The rock breakage test bed by coupled mechanical and hydraulic action is shown in Figure 9, and it mainly consists of hydraulic system, high pressure water system, control system, and acquisition system: the hydraulic system is used to realize the feeding motion of mechanical tool with different velocity and fix the broken object; high pressure water system is used to provide high pressure water $(0 \sim 80 \mathrm{MPa})$ and realize the rock fragmentation by coupled mechanical and hydraulic action; the control system is used to adjust the tool feeding velocity, water pressure, and rock position; the acquisition system is used to collect the tool displacement, oil pressure of thrust cylinder, and the pressure of water system.

The marble (Xuzhou, China) was selected as broken object, and its mode I fracture toughness was $2 \mathrm{MPa} \cdot \mathrm{m}^{1 / 2}$. The experiments of rock breakage by coupled mechanical and hydraulic action with different water pressure were done when the cutting depth was equal to $8 \mathrm{~mm}$. The kerf of rock fragmentation and the corresponding fragment are shown in Figure 10, and the reacting force of mechanical tool in rock breakage with or without hydraulic action assistance is shown in Figure 11. From the pictures, it indicates that the rock would be subject to elastic deformation and crack propagation stages under mechanical or mechanicalhydraulic action. The peak reacting force of mechanical tool by combined breakage was smaller than that of rock breakage without hydraulic action assistance, but the small difference of the two different conditions indicated that the rock breakage was mainly caused by mechanical action in these experiments. In addition, quick reduction of reacting force of mechanical tool after peak value was caused by the hydraulic action. The reasons for this phenomenon are as follows: the crack initiated after peak reacting force, and the stress intensity factor at crack tip of mode I fracture was

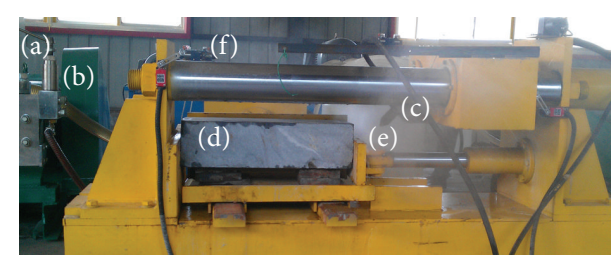

FIGURE 9: Rock fragmentation test bed by coupled mechanical and hydraulic action. (a) Acquisition system; (b) high pressure water system; (c) mechanical tool; (d) marble; (e) high pressure water; (f) hydraulic control platform.

improved by water pressure in crack; the rock fragments could be cleared away by the flowing water, which can make the subsequent rock fragment form easily. The specific energy consumption which was defined as the energy consumed per unit volume of material removal $[33,34]$ and the volume and size of rock fragments in these experiments were similar. As in the above analysis, the reacting force after peak value can be reduced obviously; thus the specific energy consumption of rock breakage by mechanical tool can be reduced assisted by low water pressure to some extent. The percentage reduction of reacting force with different water pressure assisted by hydraulic action is shown in Figure 12, and it increased with the water pressure. However, the increasing rate of low water pressure was smaller than that of high water pressure. The reason was that hydraulic impact with low water pressure produced crack difficultly, and it only can damage or weaken the rock. Therefore, the reacting force reduced inconspicuously with low water pressure. The crack could be produced by hydraulic impact when the water pressure was high, and the hydraulic action was effective in improving the crack propagation and reducing the reacting force of mechanical tool. According to Figure 8, we assumed that a crack length of $1 \mathrm{~mm}$ outside the elastic zone could be produced by mechanical tool or hydraulic impact. In theory, the percentage reduction of reacting force with low water pressure of $10 \mathrm{MPa}$ reached over $40 \%$, but it was less than $15 \%$ when the pressure is equal to $50 \mathrm{MPa}$ in these experiments. The reasons for this phenomenon are as follows: the sharpness of tool carbide tip was damaged as a result of embedding the nozzle into mechanical tool, which had detrimental effect on rock breakage and crack formation [4], and also made the rock breakage performance decline by coupled mechanical and hydraulic action; although the lowto-moderate water pressure (less than $50 \mathrm{MPa}$ ) was sufficient for hydraulic breaking of the rock in theory, the difficulty of crack formation by hydraulic impact on high strength rock restricted the rock breakage ability by combined actions to some extent. As mentioned above, the reacting force and specific energy consumption of mechanical tool could be reduced by combined breakage, but a certain length formation by mechanical tool or hydraulic impact was the key for improving the rock fragmentation ability by combined actions. Therefore, the sharpness of tool carbide tip and the ability of hydraulic impact should be considered in designing mechanical-hydraulic tool. 


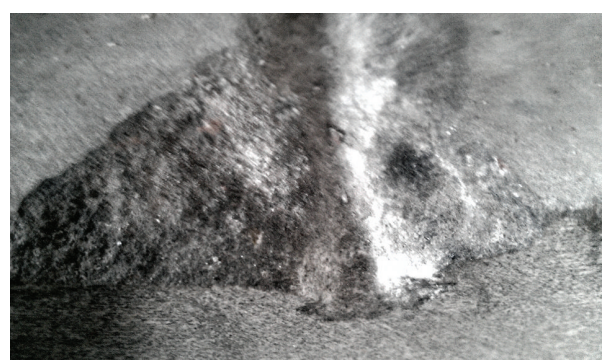

(a) The kerf of rock fragmentation

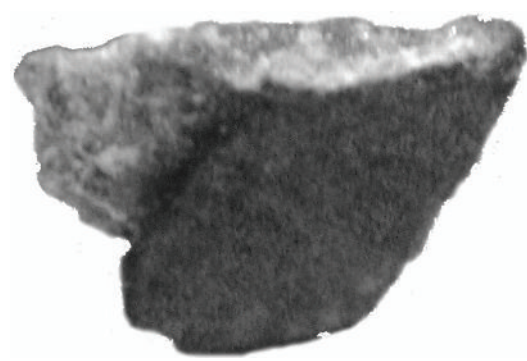

(b) Rock fragment

FIGURE 10: The state of rock fragmentation.

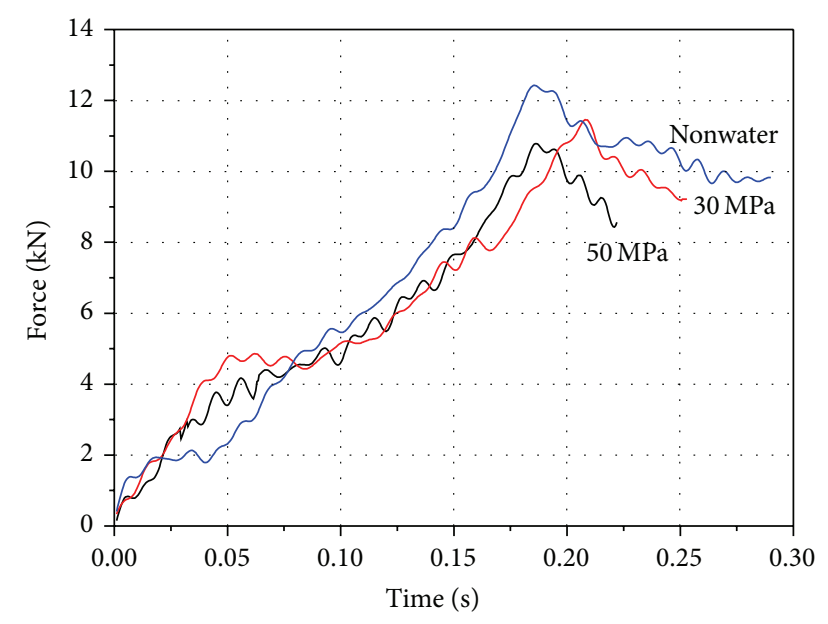

FIGURE 11: The reacting force.

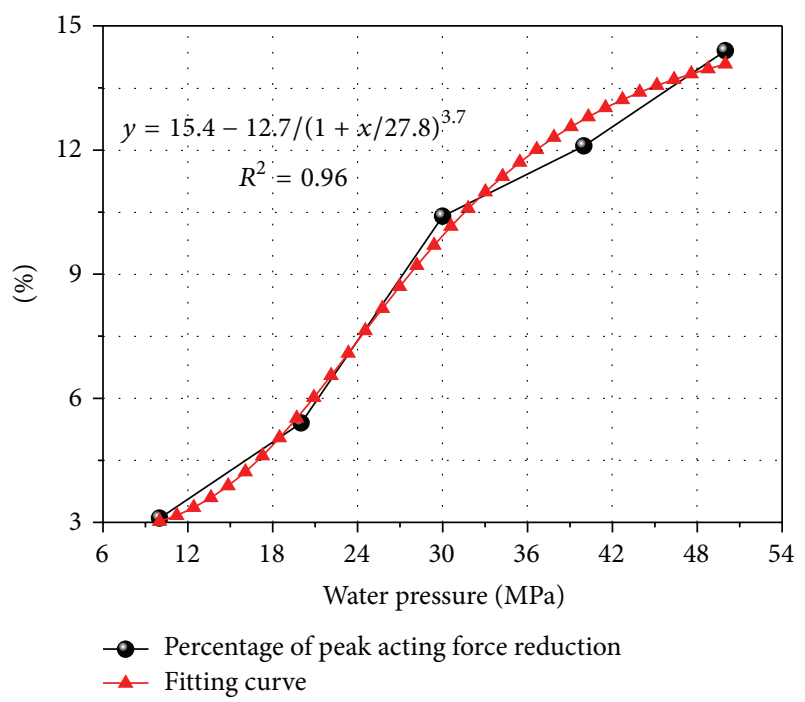

FIGURE 12: Percentage reduction of peak reacting force.

\section{Conclusions}

Based on rock fracture mechanics and the solution of Boussinesq's problem, the theoretical model of rock breakage by mechanical tool was developed. The experimental and theoretical peak reacting forces had reliable linear regression relation $\left(R^{2}=0.99\right)$, and the developed model could predicate the peak reacting force of mechanical tool approximatively. According to the superposition principle of intensity factors at the crack tip, the theoretical model of rock breakage by coupled mechanical and hydraulic action was set up. The reacting force could be reduced obviously when the crack formation was a prerequisite assisted by hydraulic action, and the percentage reduction of reacting force increased with hydraulic pressure. For the high strength marble as broken object, the experimental results indicated that the percentage reduction of peak reacting force was less than $15 \%$ with lowto-moderate water pressure (less than $50 \mathrm{MPa}$ ), but quick reduction of reacting force after peak value could reduce the specific energy consumption of rock breakage by mechanical tool. The produced crack length by mechanical or hydraulic impact was the key for improving the ability of rock breakage.

\section{Conflict of Interests}

The authors declare that there is no conflict of interests regarding the publication of this paper.

\section{Acknowledgments}

The authors would like to acknowledge the National Natural Science Foundation of China (51375478) and Fundamental Research Funds for the Central Universities (2014ZDPY12).

\section{References}

[1] C. Balci and N. Bilgin, "Correlative study of linear small and full-scale rock cutting tests to select mechanized excavation machines," International Journal of Rock Mechanics \& Mining Sciences, vol. 44, no. 3, pp. 468-476, 2007.

[2] T. K. Lu, H. Yu, T. Y. Zhou, J. S. Mao, and B. H. Guo, "Improvement of methane drainage in high gassy coal seam using waterjet technique," International Journal of Coal Geology, vol. 79, no. 1-2, pp. 40-48, 2009.

[3] S. Secchi and B. A. Schrefler, "A method for 3-D hydraulic fracturing simulation," International Journal of Fracture, vol. 178, no. 1-2, pp. 245-258, 2012.

[4] H. X. Jiang, C. L. Du, S. Y. Liu, and K. D. Gao, "Numerical simulation of rock fragmentation process by roadheader pick," Journal of Vibroengineering, vol. 15, no. 4, pp. 1807-1817, 2013. 
[5] Y. Y. Lu, J. R. Tang, Z. L. Ge, B. W. Xia, and Y. Liu, "Hard rock drilling technique with abrasive water jet assistance," International Journal of Rock Mechanics \& Mining Sciences, vol. 60, pp. 47-56, 2013.

[6] S. Liu, Z. Liu, X. Cui, and H. Jiang, "Rock breaking of conical cutter with assistance of front and rear water jet," Tunnelling and Underground Space Technology, vol. 42, pp. 78-86, 2014.

[7] R. Ciccu and B. Grosso, "Improvement of the excavation performance of PCD drag tools by water jet assistance," Rock Mechanics and Rock Engineering, vol. 43, no. 4, pp. 465-474, 2010.

[8] I. Evans, "A theory of the cutting force for point-attack picks," International Journal of Mining Engineering, vol. 2, no. 1, pp. 63$71,1984$.

[9] F. F. Roxborough and Z. C. Liu, "Theoretical considerations on pick shape in rock and coal cutting," in Proceedings of the 6th Underground Operator's Conference, pp. 189-193, Kalgoorlie, Australia, 1995.

[10] R. M. Goktan and N. Gunes, "A semi-empirical approach to cutting force prediction for point-attack picks," The Journal of the South African Institute of Mining and Metallurgy, vol. 105, no. 4, pp. 257-263, 2005.

[11] R. H. Bao, L. C. Zhang, Q. Y. Yao, and J. Lunn, "Estimating the peak indentation force of the edge chipping of rocks using single point-attack pick," Rock Mechanics and Rock Engineering, vol. 44, no. 3, pp. 339-347, 2011.

[12] G. Kuidong, D. Changlong, J. Hongxiang, and L. Songyong, "A theoretical model for predicting the Peak Cutting Force of conical picks," Frattura ed Integrita Strutturale, vol. 8, no. 27, pp. 43-52, 2014.

[13] F. P. Bowden and J. H. Brunton, "Damage to solids by liquid impact at supersonic speeds," Nature, vol. 181, no. 4613, pp. 873875,1958

[14] A. W. Momber, "Deformation and fracture of rocks due to highspeed liquid impingement," International Journal of Fracture, vol. 130, no. 3, pp. 683-704, 2004.

[15] T. K. Perkins and L. R. Kern, "Widths of hydraulic fractures," SPE Journal, vol. 13, no. 9, pp. 937-949, 1961.

[16] J. R. Rice and M. P. Cleary, "Some basic stress diffusion solutions for fluid saturated elastic porous media with compressible constituents," Reviews of Geophysics, vol. 14, no. 2, pp. 227-241, 1976.

[17] M. P. Cleary, "Moving singularities in elasto-diffusive solids with applications to fracture propagation," International Journal of Solids and Structures, vol. 14, no. 2, pp. 81-97, 1978.

[18] M. Hood, "Cutting strong rock with a drag bit assisted by highpressure water jets," Journal of The South African Institute of Mining and Metallurgy, vol. 77, no. 4, pp. 79-90, 1976.

[19] X. B. Li, D. A. Summers, G. Rupert, and P. Santi, "Experimental investigation on the breakage of hard rock by the PDC cutters with combined action modes," Tunnelling and Underground Space Technology, vol. 16, no. 2, pp. 107-114, 2001.

[20] R. Ciccu and B. Grosso, "Improvement of disc cutter performance by water jet assistance," Rock Mechanics and Rock Engineering, vol. 47, no. 2, pp. 733-744, 2014.

[21] J. R. Rice, "Mathematical analysis in the mechanics of fracture," in Fracture: An Advanced Treatise, vol. 2, pp. 191-311, Academic Press, New York, NY, USA, 1968.

[22] I. S. Sokolnikoff, Mathematical Theory of Elasticity, McGrawHill, New York, NY, USA, 1956.
[23] J. P. Loui and U. M. R. Karanam, "Numerical studies on chip formation in drag-pick cutting of rocks," Geotechnical and Geological Engineering, vol. 30, no. 1, pp. 145-161, 2012.

[24] J. Boussinesq, Application des potentiels à l'étude de l'équilibre et du mouvement des solides élastiques: principalement au calcul des déformations et des pressions que produisent, dans ces solides, des efforts quelconques exercés sur une petite partie de leur surface ou de leur intérieur : mémoire suivi de notes étendues sur divers points de physique, mathematique et d'analyse, Gauthier-Villars, 1885.

[25] B. Chiaia, "Fracture mechanisms induced in a brittle material by a hard cutting indenter," International Journal of Solids and Structures, vol. 38, no. 44-45, pp. 7747-7768, 2001.

[26] X. Duan, L. Yu, and D. Z. Cheng, "Chaotic dynamical features of rock breakage mechanism with self-controlled hydro-pick," Chinese Journal of Rock Mechanics and Engineering, vol. 14, pp. 484-491, 1995.

[27] S. Liu, J. Chen, and X. Liu, "Rock breaking by conical pick assisted with high pressure water jet," Advances in Mechanical Engineering, vol. 2014, Article ID 868041, 10 pages, 2014.

[28] B. Aamodt and P. G. Bergan, "On the principle of superposition for stress intensity factors," Engineering Fracture Mechanics, vol. 8, no. 2, pp. 437-440, 1976.

[29] H. L. Ewalds and J. H. Wanhill, Fracture Mechanics, Edward Arnord Pty, Sydney, Australia, 1984.

[30] Y. Murakami, Stress Fntensity Factors Handbook, Pergamon Press, New York, NY, USA, 1986.

[31] Y.-Y. Lu, S. Zhang, Y. Liu, Z.-H. Lu, and L.-Y. Jiang, "Analysis on stress wave effect during the process of rock breaking by pulsed jet," Journal of Chongqing University, vol. 35, no. 1, pp. 117-124, 2012.

[32] H. Jiang, C. Du, S. Liu, and K. Gao, "Numerical simulation of rock fragmentation under the impact load of water jet," Shock and Vibration, vol. 2014, Article ID 219489, 11 pages, 2014.

[33] R. Teale, "The concept of specific energy in rock drilling," International Journal of Rock Mechanics and Mining Sciences of Geomechanics Abstracts, vol. 2, no. 1, pp. 57-73, 1965.

[34] M. Yurdakul, K. Gopalakrishnan, and H. Akdas, "Prediction of specific cutting energy in natural stone cutting processes using the neuro-fuzzy methodology," International Journal of Rock Mechanics and Mining Sciences, vol. 67, pp. 127-135, 2014. 


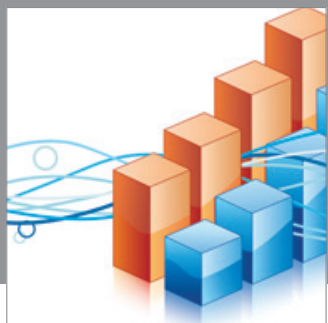

Advances in

Operations Research

mansans

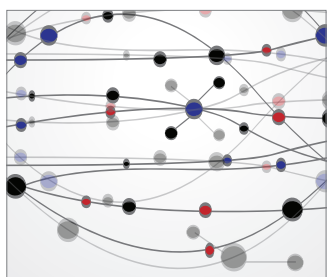

The Scientific World Journal
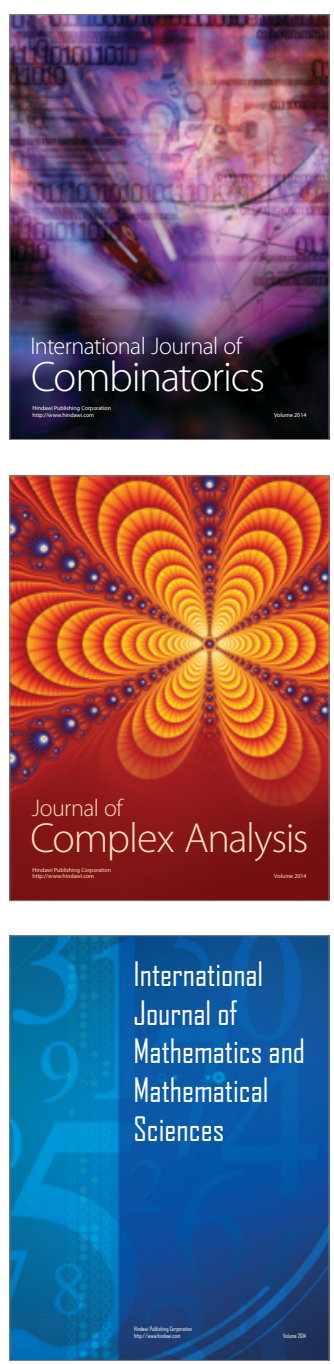
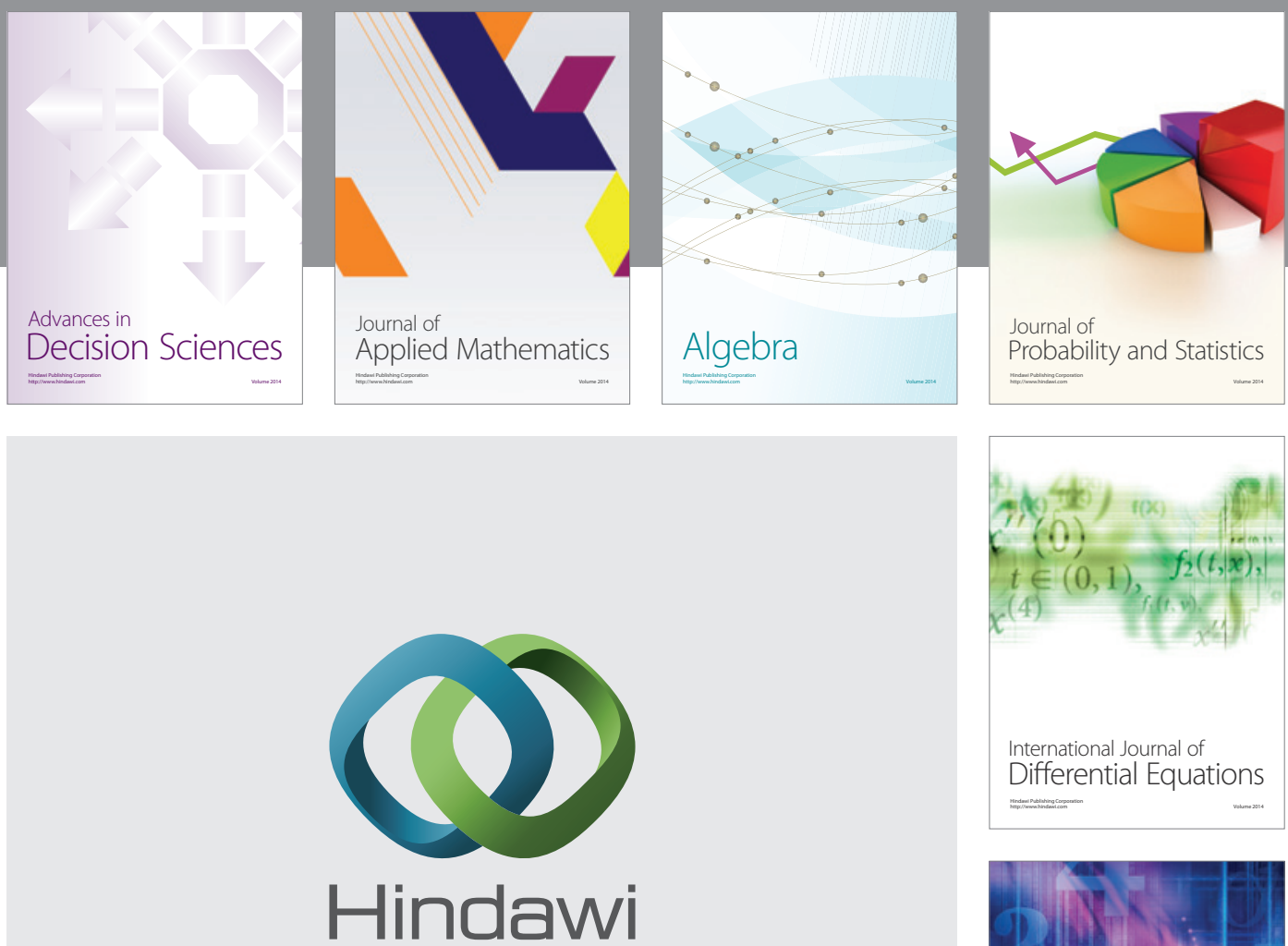

Submit your manuscripts at http://www.hindawi.com
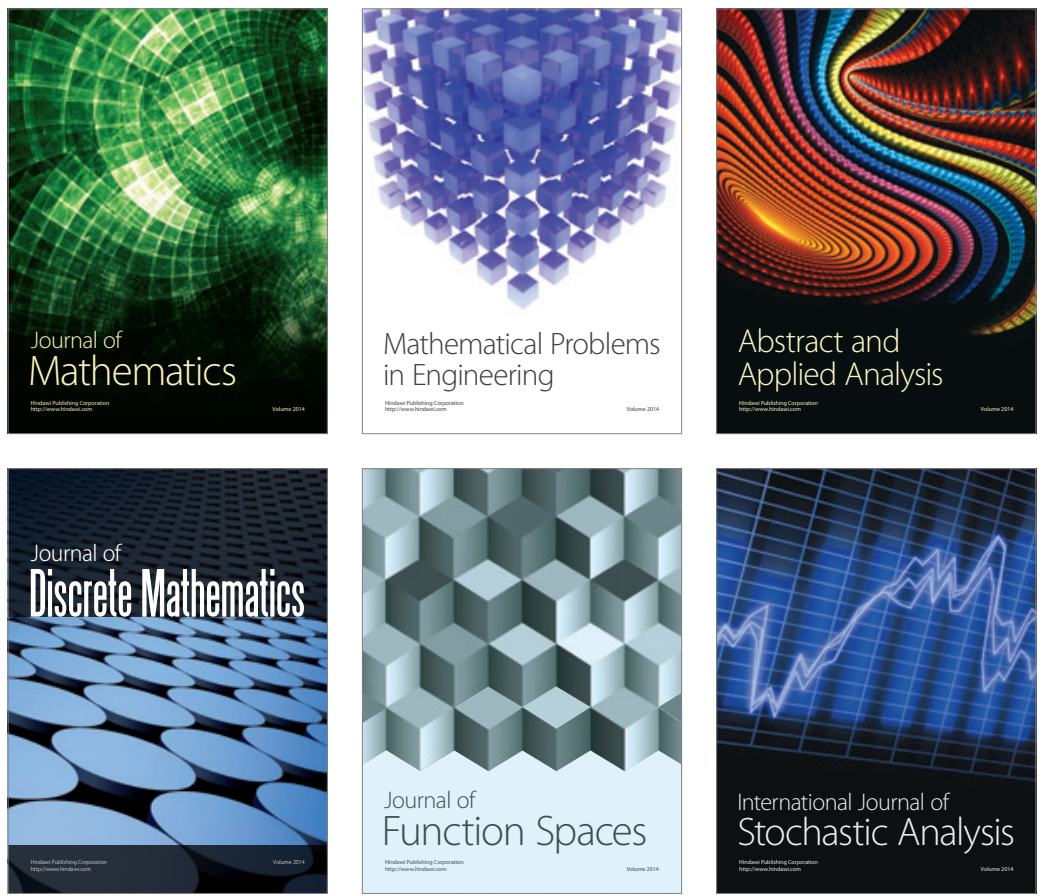

Journal of

Function Spaces

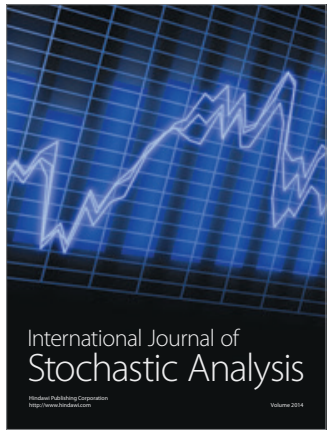

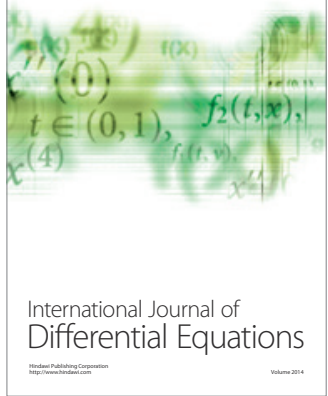
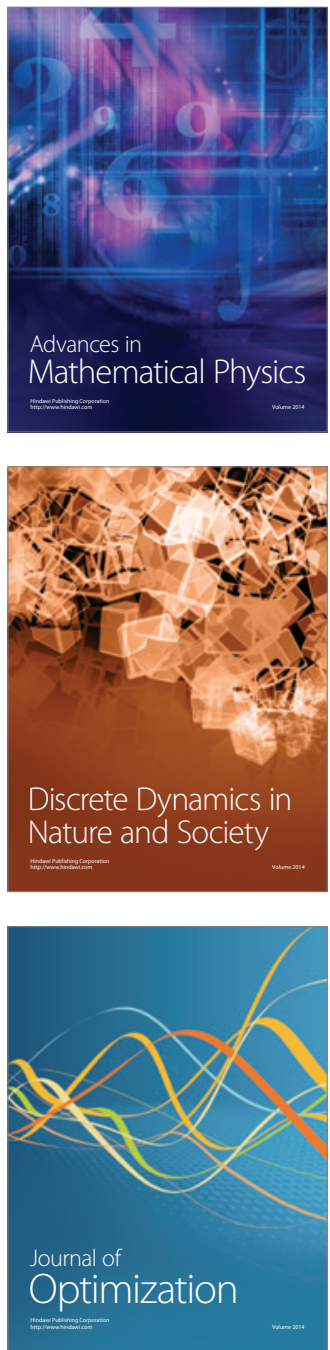